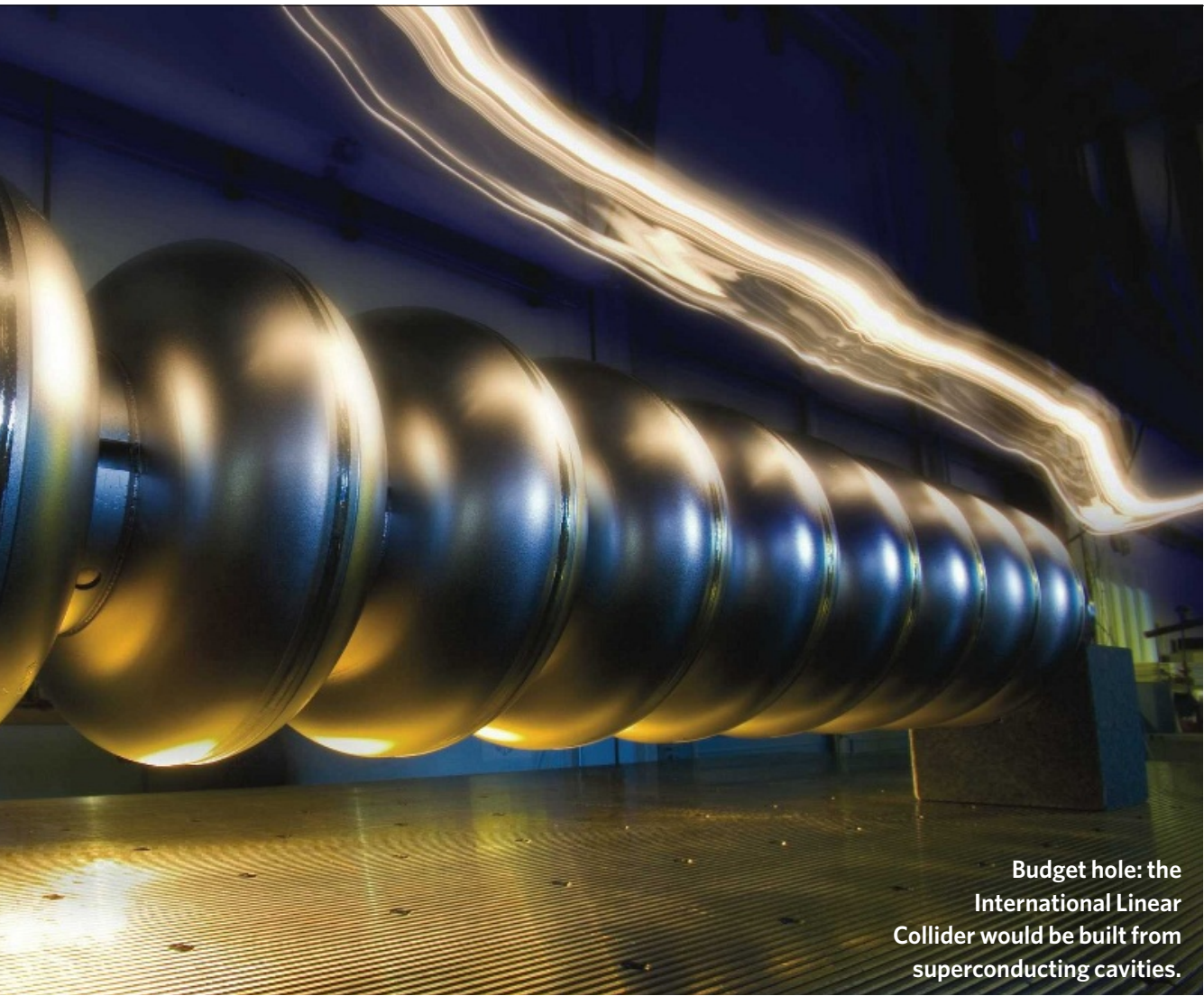

accelerators. Holmes is unsure why Congress slashed the project's funding, but the US government announced a tighter budget for the rest of science too, in part due to the cost of the Iraq war (see Nature 451, 2; 2008).

Physicists in other partner nations do not expect the withdrawals to undermine their own governments' commitments to the collider. In Japan, this year's budget for highenergy physics is already assured - although the government has not yet decided whether it will support the collider - says Mitsuaki Nozaki, a physicist at KEK, the high-energy accelerator research organizarion in Tsukuba and Asian regional director for the collider's design effort. In Germany, work on the superconducting cavities that make up the core of the accelerator will continue, says Rolf-Dieter Heuer, who heads research at the German electron synchrotron, DESY, in Hamburg.

But the prospects for building the machine are murkier now than at any previous point during its planning. Many had hoped that the United States might offer to host the project at Fermilab, but even before the cuts Raymond Orbach, who heads the US Department of Energy's Office of Science, called for the collider to be delayed until results come from the LHC in a few years' time.

"You need the results from the LHC to say if the ILC energies are high enough," Richter says. "Nobody wants to build a machine that isn't going to do anything."

Keith Mason, who heads the UK Science and Technology Facilities Council, has gone further, saying the plan for the accelerator "is not credible financially, politically or in any other way".

Nevertheless, the project's supporters plan to soldier on. Barish says the group will divert research from the United States in an effort to salvage the design phase, and Foster says UK physicists are campaigning to bring the nation back into the project.

Richter says all eyes are on the US budget for 2009 to see if 2008 was a one-year dip. "If something isn't done in the president's budget submission in February or in some kind of supplemental bill, I think the ILC as we now see it is in very big trouble."

Eric Hand and Geoff Brumfiel

See Editorial, page 108.

\title{
Could global gardening fix climate change?
}

Using biomass fuel on a massive scale in combination with carbon sequestration could return atmospheric carbon dioxide to pre-industrial levels within decades, according to a new analysis.

Peter Read calls his proposal global gardening. To make it work, an area the size of France and Germany would have to be enlisted for growing biomass fuels for a quarter of a century .

"This is the first time it's been demonstrated that you can manage carbon levels in the atmosphere" using biomass, says Read, an economist at Massey University's Centre for Energy Research in Palmerston North, New Zealand. Such a move may be necessary to avoid abrupt climate change, he says.
Referees at the journal Climatic Change rejected Read's paper, but editor Stephen Schneider elected to publish it as an editorial commentary.

"Peter has some very clever and controversial ideas," says Schneider, a climatologist at Stanford University in California. "Climatic Change has long been a venue where clever and controversial ideas can get aired - as long as they are in perspective."

Read envisions an array of plantations supplying commodities such as energy and timber, as well as a livelihood for countless communities. A second phase could combine biomass energy with carbon sequestration, moving society to the point where it sequestered more carbon than it emitted.

Gregg Marland, a climate researcher currently working at the International

\section{"You can manage Institute for Applied Systems} carbon dioxide Analysis in Laxenburg, Austria using biomass." has numerous doubts about the proposal, including crop productivity, implementation and land use. He co-authored a commentary suggesting that it's unclear whether Read's vision is "a dream or a nightmare".

But it's still a useful thought experiment, he says. "I think what Peter has done is paint a picture: if we really get into trouble with carbon dioxide, how can we back off?" Jeff Tollefson 